\title{
Variability, Heritability and Genetic advance of introduced upland rice genotypes at Fogera in North Western Ethiopia
}

\author{
Mersha Tezera ${ }^{1}$ \\ ${ }^{1}$ Ethiopian Biodiversity Institute, Bahir Dar Biodiversity Center, Ethiopia \\ Correspondence: Mersha Tezera, Ethiopian Biodiversity Institute, Bahir Dar Biodiversity Center, Ethiopia. Tel: \\ 251-093-286-2658. E-mail: mertez19@yahoo.com
}

\author{
Received: April 3, 2021 \\ Accepted: September 7, $2021 \quad$ Online Published: September 10, 2021 \\ doi:10.5539/jps.v10n2p30 \\ URL: https://doi.org/10.5539/jps.v10n2p30
}

\begin{abstract}
Variability, heritability and genetic advance are basic in order to provide information for plant breeding programs. Forty nine upland rice genotypes were tested in $7 * 7$ simple lattice design at Fogera in Wereta station of Adet Agricultural Research Center in 2012/13. The objectives of the study were to estimate the genetic variability, heritability and genetic advance of the genotypes tested. Analysis of variance revealed that there was highly significant difference among the 49 genotypes for all the characters studied. Accessions IR 78937-B-3-B-B-1 and IR 78937-B-3-B-B-2 had the highest yield with a score of $5374.5 \mathrm{~kg} / \mathrm{ha}$ and $5305.6 \mathrm{~kg} / \mathrm{ha}$ respectively. The high yielding genotype IR 78937-B-3-B-B-1 had a yield advantage of $57 \%$ and $22.2 \%$, respectively, as compared to standard checks Nerica-4 and Hidasie. Phenotypic coefficient of variation (PCV) values ranged from $2.5 \%$ for panicle length to $49.98 \%$ for number of spikelet per panicle. While the genotypic coefficient of variation (GCV) ranged from $2.4 \%$ for panicle length to $47.6 \%$ for number of spikelet per panicle. Number of tiller per plant (22.47\%), number spikelet per panicle (49.98\%), thousand seed weight $(25.56 \%)$ and yield $(23.93 \%)$ had higher PCV values. The PCV values for flag leaf length (14.79\%), flag leaf width $(16.12 \%)$, and culm length (16.42\%) and number of panicle per plant $(16.32 \%)$ were medium. Flowering cycle $(7.81 \%)$, maturation cycle $(2.9 \%)$, and panicle length (2.5\%) had lower PCV values. GCV values were low for flowering cycle $(7.21 \%)$, maturation cycle $(1.82 \%)$ and panicle length $(2.4 \%)$; medium for flag leaf length (14.26\%), flag leaf width $(15.39 \%)$, culm length $(15.19 \%)$ and number of panicle per plant $(15.72 \%)$; high for number of tillers per plant $(22.18 \%)$, yield (23.07\%), thousand seed weight $(25.18 \%)$ and number of spikelet per panicle $(47.60 \%)$. The high GCV values of these characters suggest that genetic impact is higher and environmental influence is lower. This study generally had indicated that there was significant genetic variability or divergence among the genotypes. Thus, the improvement program of the upland rice genotypes through direct selection rather than a lengthy crossing program is recommended.
\end{abstract}

Keywords: variability, heritability, morphological traits

\section{Introduction}

Rice belongs to the genus Oryzae, and is one of the leading food crops in the world. As such, it is a staple food of over a half of the world's population, mostly in Asia. It is the second most cultivated cereal after wheat. It is the world's most important food crop, which occupies $11 \%$ of the world's total arable land; it supplies 2,808 calories/person/day, which represents $21 \%$ of the total calorie supply. It is source of income for more than 100 million householders around the world and is one of the crops responsible for the so-called green revolution that happened in the 1960s and 1970s. Upland rice is one of the main staple crop or staple food in inter-tropical highland areas. It is grown in rainfed, naturally well-drained soils without surface water accumulation, usually without water logging. Land slopes vary from 0 to more than 30\% (IRRI, 2013).

Rice cultivation and its utilization as a food crop in Ethiopia is a very recent phenomenon. The cultivation of the crop has begun at Fogera, Amhara Region and Gambella plains in the early 1970's. Currently, Fogera, Gambella, Metema, and Pawe are major rice producing areas in Ethiopia. The occurrence of wild rice Oryza longistaminata in the swampy and water logged areas of Fogera locally known as Zurha and Gambella plains is believed to have prompted the cultivation of the crop at these locations. Subsequently, rice adaptation and screening experiments were initiated and conducted at Fogera, Gambella, Werer, Debre Zeit, and Arba Minch since its introduction in the 1970's (Mulugeta Seyoum, 1999). 
Knowledge on the extent and pattern of genetic variability present in a population is absolutely essential for further improvement of the crop. Besides, knowledge of the naturally occurring diversity in a population helps to identify diverse groups of genotypes that can be useful for the breeding program. Such information is scarce in upland rice production system of Ethiopia. Hence, the present study is initiated with the following objectives:

\section{Objective}

To assess the magnitude of variability, heritability and genetic advance for traits as well as to estimate the genetic divergence among tested genotypes.

\subsection{Materials Used and Experimental Design}

Forty-nine upland genotypes/lines which are comprised from different preliminary variety trials and variety adaptation trial accessions were evaluated together with two standard check varieties. The experiment was conducted in a simple lattice design with two replications. The experimental plots were prepared by tractor ploughing and harrowing. Clean seeds of each genotype were selected and planted on well prepared plots. The plot size was $2.5 \mathrm{~m}$ long and $0.4 \mathrm{~m}$ wide, consisting of two rows per plot with $20 \mathrm{~cm}$ spacing between them and $0.3 \mathrm{~m}$ spacing between plots as well as $1 \mathrm{~m}$ spacing between blocks. Sowing was done by hand drilling at a seed rate of $60 \mathrm{~kg} / \mathrm{ha}$. Nitrogen was applied in the form of urea at the rate of $100 \mathrm{~kg} / \mathrm{ha}$, in three splits, i.e., one-third at planting, tillering and panicle initiation. Phosphorus was applied in the form of Di-Amonium phpsphate (DAP) at the rate of $100 \mathrm{~kg} / \mathrm{ha}$ at planting. All other management practices were uniformly applied to all plots using recommended practices. Data on plot and plant basis was collected. Data on plant basis were recorded by randomly taking six plants from each experimental plot. 
Table 1. Forty nine upland genotypes/accessions used in the study

\begin{tabular}{|c|c|c|}
\hline Entry no & Genotypes & Seed source \\
\hline $\mathbf{1}$ & IR 28635-B-B-23-1 & AARC \\
\hline 2 & IR 83399-B-B-52-1 & “ \\
\hline 3 & IR 82310-B-B-67-2 & “ \\
\hline 4 & IR 82639-B-B-115-1 & “ \\
\hline 5 & IR 79915-B-83-4-3 & “ \\
\hline 6 & IR 78937-B-4-B-B-B & “ \\
\hline 7 & IR 82319-B-B-103-2 & “ \\
\hline 8 & IR 78913-B-10-B-B-B & “ \\
\hline 9 & IR 78877-048-B-B-3 & “ \\
\hline 10 & IR 78948-B-1-B-B-B & “ \\
\hline 11 & UPLR1-7 & “ \\
\hline 12 & IR 78937-B-3-B-B-2 & “ \\
\hline 13 & IR 82039-B-B-103-4 & “ \\
\hline 14 & IR 82635-B-B-32-4 & “ \\
\hline 15 & IR 82638-B-B-147-1 & “ \\
\hline 16 & IR 82639-B-B-118-3 & “ \\
\hline 17 & IR 82589-B-B-114-3 & “ \\
\hline 18 & IR 82635-B-B-58-1 & “ \\
\hline 19 & IR 82635-B-B-88-2 & “ \\
\hline 20 & IR 82639-B-B-140-1 & “ \\
\hline 21 & IR 82635-B-B-4 7-1 & “ \\
\hline 22 & IR 82635-B-B-72-2 & “ \\
\hline 23 & IR 82589-B-B-7-2 & “ \\
\hline 24 & IR 78937-B-3-B-B-1 & “ \\
\hline 25 & IR 78940-B-22-B-B-B-5B1 & “ \\
\hline 26 & IR 77298-14-1-2-10 & “ \\
\hline 27 & KMP34 & “ \\
\hline 28 & IR 60080-46A & “ \\
\hline 29 & ACCU16 bar 9-16-17-3-B-1 & “ \\
\hline 30 & ACCU 16 bar 5-6-22-2B-1 & “ \\
\hline 31 & ACCU 16 bar 12-13-14-B-1 & “ \\
\hline 32 & ACCU 16 bar $12-12-33-2 B-1$ & “ \\
\hline 33 & ACCU 16 bar $15-3-22-2-B-B$ & “ \\
\hline 34 & ACCU 16 bar 12-14-19-3-B-B & “ \\
\hline 35 & ACCU 16 bar 9-4-16-3-B-1 & “ \\
\hline 36 & ACCU 16 bar $13-13-2-2-B-B$ & “ \\
\hline 37 & ACCU 16 bar 9-7-20-4-B-B & “ \\
\hline 38 & ACCU 16 bar $4-8-17-2-8-8$ & “ \\
\hline 39 & NERICA 11 & “ \\
\hline 40 & FOFIFA 3730 & “ \\
\hline 41 & FOFIFA 3737 & “ \\
\hline 42 & NERICA 14 & AARC \\
\hline 43 & NERICA 15 & “ \\
\hline 44 & NERICA 8 & “ \\
\hline 45 & NERICA 9 & “ \\
\hline 46 & NERICA 15 & “ \\
\hline 47 & FOFIFA 4129 & “ \\
\hline 48 & NERICA 4 (Check) & “ \\
\hline 49 & HIDASIE (Check) & “ \\
\hline
\end{tabular}

\subsection{Methods of Data Collection}

Quantitative descriptors were used to collect data. The data for the following characters were recorded from six randomly taken plants from each experimental plot and the average was used to in subsequent data manipulation. 
- Culm length $(\mathrm{cm})$ : measures from the base of the plant to the base of the panicle

- Flag leaf length $(\mathrm{cm})$ : measures length of the flag leaf, from the ligule to the tip of the blade.

- Flag leaf width $(\mathrm{cm})$ : measures width at the widest portion of the flag leaf

- Number of tillers per plant: recorded as the total number of grain-bearing and non bearing tillers

- Number of panicles per plant: number of primary panicle branches attached to the basal whorl of the panicle.

- Panicle length $(\mathrm{cm})$ : Length of main axis of panicle measured from the panicle base to the tip

- Number of spikelets per panicle: total counted spikelets within a single panicle

- Flowering cycle: Number of days until $50 \%$ flowering starting from germination

- Maturation Cycle: Number of days until $50 \%$ of the panicles matured

- 1000-grain weight (gm): Random sample of 1000 well-developed, whole grains and dried to $13 \%$ moisture content weigh on a precision balance

- Grain yield $(\mathrm{kg})$ : estimated from the harvestable rows of the plot

\subsection{Data Analysis}

\subsubsection{Analysis of Variance}

Analysis of variance (ANOVA) was conducted using SAS computer software program following SAS (Version 9.1) statement for simple lattice design.

\subsubsection{Estimation of Genetic Parameters}

Estimation of variance components

The phenotypic and genotypic coefficients of variation were estimated according to the method suggested by Burton and de Vane (1953) as follows: -

Environmental variance $\left(\sigma^{2} \mathrm{e}\right)=\mathrm{MS}_{\mathrm{e}}$

Genotypic variance $\left(\sigma^{2} \mathrm{~g}\right)=\left[\frac{M S_{g}-M S_{e}}{r}\right]$

Phenotypic variance $\left(\sigma^{2} \mathrm{p}\right)=\sigma^{2} \mathrm{~g}+\sigma^{2} \mathrm{e}$

Phenotypic coefficient of variation $(\mathrm{PCV})=\frac{\widetilde{D}}{\bar{x}} \times 100$

Genotypic coefficient of variation $(\mathrm{GCV})=\frac{\sigma_{g}}{\bar{x}} \times 100$, Where, $\bar{x}=$ grand mean of character. Generally, quantitative characters or traits could be highly influenced by environment which could be estimated through the combination genotypic (GCV), phenotypic (PCV) and environmental (ECV) coefficient of variations. According to Deshmukh et al. (1986), PCV and GCV values $>20 \%$ are regarded as high, values $<10 \%$ are considered to be low and values between $10 \%$ and $20 \%$ to be medium.

\subsubsection{Estimation of Heritability in Broad Sense}

Broad sense heritability $\left(\mathrm{h}^{2}\right)$ expressed as the percentage of the ratio of the genotypic variance ( $\sigma^{2} \mathrm{~g}$ ) to the phenotypic variance $\left(\sigma^{2} \mathrm{p}\right)$ and was estimated on genotype mean basis as described by Allard (1960) as:

$$
\mathrm{h}^{2}=\left[\frac{\sigma_{g}^{2}}{\sigma_{p}^{2}}\right] x 100
$$

\section{Results and Discussion}

The result of analysis of variance (ANOVA) of 11 quantitative characters for the 49 upland rice genotypes is 
presented in Table 2. There was highly significant difference $(\mathrm{P}<0.01)$ among the tested genotypes indicating variation in measured traits. Veasey et al. (2008) also found significant differences and high variability for traits of Oryza glumaepatula mainly for the characters number of tillers, plant height at flowering, leaf length and width, culm length, days to heading, panicle number, panicle height, flag leaf length, spikelet length and awn length. Simple lattice was more efficient over RCBD in detecting variation of most characters except flag leaf width $(98.41 \%)$, number of panicle per plant (94.34\%), and number of spikelet per panicle $(90.43 \%)$.

Table 2. Analysis of variance for 11 quantitative characters of 49 upland rice genotypes evaluated at Fogera $2012 / 13$

\begin{tabular}{|c|c|c|c|c|c|c|c|c|c|c|c|c|}
\hline \multirow{2}{*}{$\begin{array}{l}\text { Source of } \\
\text { variation }\end{array}$} & \multicolumn{12}{|c|}{ Mean squares } \\
\hline & DF & FLL & FLW & $\mathrm{CL}$ & NTPP & $\mathrm{FC}$ & $\mathrm{MC}$ & NPP & NSPP & PL & TSW & YLD \\
\hline Replication & 1 & 8.75 & 0.11 & 3.94 & 3.21 & 2.15 & 0.26 & 4.88 & 3.63 & 3.81 & 5.87 & 94178 \\
\hline $\begin{array}{l}\text { Treatment } \\
\text { Undj. }\end{array}$ & 48 & $27.68^{* * *}$ & $0.13^{* *}$ & $235.38^{* *}$ & $7.03^{* *}$ & $109.86^{* *}$ & $21.5^{* *}$ & $3.77^{* *}$ & $168.83^{* *}$ & $6.46^{* *}$ & $77.73^{* *}$ & $1676924^{* *}$ \\
\hline $\begin{array}{l}\text { Blocks with } \\
\text { in } \operatorname{reps}(\mathbf{A d j})\end{array}$ & 12 & 0.17 & 0.003 & 0.77 & 0.16 & 14.62 & 11.46 & 0.11 & 0.27 & 0.24 & 1.23 & 81753 \\
\hline Error & & & & & & & & & & & & \\
\hline Intrablock & 36 & 0.12 & 0.004 & 0.43 & 0.09 & 8.80 & 9.38 & 0.14 & 0.4350 & 0.23 & 1.17 & 53500 \\
\hline RCBD & 48 & 0.13 & 0.004 & 0.51 & 0.11 & 10.25 & 9.90 & 0.13 & 0.3934 & 0.23 & 1.18 & 60564 \\
\hline $\begin{array}{l}\text { Relative } \\
\text { Efficiency to } \\
\text { RCBD (\%) }\end{array}$ & & 101.99 & 98.41 & 107.81 & 107.43 & 105.99 & 100.96 & 94.34 & 90.43 & 100.06 & 100.06 & 104.2 \\
\hline $\begin{array}{l}\text { Coefficient of } \\
\text { variation }(\%)\end{array}$ & & 2.12 & 4.54 & 1.067 & 4.83 & 3.23 & 2.30 & 5.43 & 0.92 & 2.84 & 4.61 & 6.35 \\
\hline
\end{tabular}

\section{Mean, Range and Estimates of Genetic Parameters}

\subsection{Mean and Range}

There was wide variation from seed yield which ranged from $1556.5 \mathrm{~kg} / \mathrm{ha}$ to $5374.5 \mathrm{~kg} / \mathrm{ha}$ with a mean of $3883.7 \mathrm{~kg} / \mathrm{ha}$, Which indicates that the genotypes tested have divergence base which will have importance for future breeding and selection. Accessions IR 78937-B-3-B-B-1 and IR 78937-B-3-B-B-2 had the highest yield with a score of $5374.5 \mathrm{~kg} / \mathrm{ha}$ and $5305.6 \mathrm{~kg} / \mathrm{ha}$ respectively. The high yielding genotype IR 78937-B-3-B-B-1 had a yield advantage of $57 \%$ and $22.2 \%$, respectively, as compared to standard checks Nerica-4 and Hidasie.

In the study of genetic variability for yield and related attributes of upland rice genotypes in semi arid zone, the high yielding genotypes were found to be WAB891 SG14, WAB981 SG33 and Yunlu №.30 with grain yields of $3,600 \mathrm{~kg}, 3,500 \mathrm{~kg}$ and 3,400 kg respectively (Khalid et al., 2012). This actually is very far result as compared to the finding of this study. 
Table 3. Mean performance of 49 upland rice accessions for eleven quantitative characters tested at Fogera $2012 / 13$

\begin{tabular}{|c|c|c|c|c|c|c|c|c|c|c|c|}
\hline Genotypes & FLL & FLW & $\mathbf{C L}$ & NTPP & FC & MC & NPP & NSPP & PL & TSW & YLD \\
\hline IR 28635-B-B-23-1 & 28.7 & 1.8 & 68.5 & 10.6 & 103.3 & 139.5 & 9.7 & 85.4 & 20.5 & 16 & 4230 \\
\hline IR 83399-B-B-52-1 & 24.9 & 1.5 & 71.5 & 9.7 & 93.2 & 135.5 & 10.1 & 68.8 & 19.8 & 22 & 4059 \\
\hline IR 82310-B-B-67-2 & 24.9 & 1.3 & 72.4 & 9.4 & 100.1 & 135.0 & 8.5 & 60.8 & 22.9 & 24 & 5107 \\
\hline IR 82639-B-B-115-1 & 25.4 & 1.4 & 66.9 & 9.7 & 103.4 & 134.0 & 8.6 & 71.0 & 20.9 & 22 & 5038 \\
\hline IR 79915-B-83-4-3 & 21.7 & 1.3 & 69.8 & 7.6 & 96.1 & 131.0 & 9.9 & 68.6 & 19.7 & 20 & 4321 \\
\hline IR 78937-B-4-B-B-B & 26.7 & 1.6 & 59.6 & 10.8 & 106.7 & 140.0 & 7.0 & 62.0 & 19 & 20 & 4401 \\
\hline IR 82319-B-B-103-2 & 28.5 & 1.9 & 68.4 & 8.7 & 96.0 & 134.5 & 8.8 & 67.3 & 18.9 & 25 & 4764 \\
\hline IR 78913-B-10-B-B-B & 25.9 & 1.9 & 61.1 & 6.0 & 107.1 & 131.5 & 12.5 & 75.8 & 18 & 25 & 4129 \\
\hline IR 78877-048-B-B-3 & 21.7 & 1.3 & 61 & 10.9 & 109.1 & 138.5 & 7.9 & 70.5 & 15.5 & 17 & 1557 \\
\hline IR 78948-B-1-B-B-B & 21.5 & 1.5 & 68.6 & 7.0 & 97.0 & 133.0 & 6.4 & 65.8 & 20.9 & 22 & 3074 \\
\hline UPLR1-7 & 32.8 & 2 & 52.7 & 6.9 & 109.2 & 136.5 & 6.3 & 58.5 & 18.7 & 20 & 3068 \\
\hline IR 78937-B-3-B-B-2 & 31.8 & 1.8 & 62.7 & 9.7 & 112.5 & 141.5 & 9.5 & 65.0 & 19.8 & 21 & 5306 \\
\hline IR 82039-B-B-103-4 & 29.7 & 1.7 & 82.8 & 9.8 & 97.1 & 135.5 & 10.6 & 74.3 & 18.3 & 23 & 3536 \\
\hline IR 82635-B-B-32-4 & 30 & 1.9 & 72.8 & 7.1 & 100.9 & 138.0 & 7.9 & 78.5 & 21.8 & 22 & 5186 \\
\hline IR 82638-B-B-147-1 & 32.7 & 1.7 & 63.9 & 9.9 & 105.7 & 135.0 & 9.5 & 92.5 & 18.5 & 20 & 5154 \\
\hline IR 82639-B-B-118-3 & 25.8 & 1.5 & 63.2 & 8.8 & 108.1 & 135.0 & 11.8 & 86.1 & 23.1 & 22 & 3876 \\
\hline IR 82589-B-B-114-3 & 25.6 & 1.6 & 62.3 & 11.6 & 107.5 & 137.5 & 10.5 & 82.8 & 22.1 & 16 & 4041 \\
\hline IR 82635-B-B-58-1 & 21 & 1.5 & 69.1 & 9.0 & 103.2 & 135.0 & 8.5 & 88.2 & 21 & 20 & 4432 \\
\hline IR 82635-B-B-88-2 & 26.5 & 1.5 & 66 & 8.5 & 100.0 & 135.0 & 9.1 & 76.3 & 20 & 20 & 4851 \\
\hline IR 82639-B-B-140-1 & 31.5 & 1.5 & 72 & 7.5 & 99.6 & 133.0 & 9.8 & 70.7 & 20.8 & 24 & 4367 \\
\hline IR 82635-B-B-4 7-1 & 26.3 & 1.7 & 66 & 6.8 & 99.4 & 133.0 & 9.5 & 77.5 & 17.6 & 27 & 2322 \\
\hline IR 82635-B-B-72-2 & 24.5 & 1.5 & 56.9 & 7.6 & 103.6 & 133.5 & 7.7 & 72.7 & 15.8 & 19 & 3602 \\
\hline IR 82589-B-B-7-2 & 25.3 & 1.7 & 54.2 & 6.4 & 108.5 & 138.5 & 7.8 & 72.8 & 18.5 & 16 & 2842 \\
\hline IR 78937-B-3-B-B-1 & 21.7 & 1.7 & 78.8 & 8.5 & 99.4 & 132.0 & 8.4 & 92.3 & 19.5 & 26 & 5375 \\
\hline IR 78940-B-22-B-B-B-5B1 & 28.8 & 1.7 & 56.6 & 7.9 & 102.7 & 136.0 & 9.6 & 76.8 & 20.5 & 20 & 5234 \\
\hline IR 77298-14-1-2-10 & 31.5 & 1.9 & 74.9 & 7.4 & 103.4 & 135.0 & 8.5 & 82.8 & 19.8 & 24 & 4946 \\
\hline
\end{tabular}

Table 4. Mean performance of the 49 upland rice accessions for the eleven quantitative characters tested at Fogera 2012/2013 (Continued)

\begin{tabular}{|c|c|c|c|c|c|c|c|c|c|c|c|}
\hline KMP34 & 19.8 & 1.1 & 51.6 & 11.5 & 100.0 & 139.0 & 6.8 & 52.7 & 18.5 & 20 & 3117 \\
\hline IR 60080-46A & 19.7 & 1.1 & 43.7 & 9.9 & 101.8 & 141.0 & 6.5 & 69.8 & 15 & 18 & 4939 \\
\hline ACCU16 bar 9-16-17-3-B-1 & 27.8 & 2.2 & 77.8 & 7.6 & 103.8 & 140.0 & 9.6 & 70.1 & 21.5 & 23 & 2683 \\
\hline ACCU 16 bar 5-6-22-2B-1 & 26.3 & 2.1 & 84.5 & 8.6 & 78.8 & 136.0 & 9.5 & 69.5 & 20.5 & 17 & 3914 \\
\hline ACCU 16 bar 12-13-14-B-1 & 29.9 & 2 & 94.8 & 5.7 & 87.7 & 138.0 & 9.8 & 84.0 & 19.8 & 26 & 3200 \\
\hline ACCU 16 bar 12-12-33-2B-1 & 25.8 & 1.8 & 84.1 & 7.5 & 88.9 & 135.0 & 9.0 & 69.7 & 21 & 26 & 3114 \\
\hline ACCU 16 bar 15-3-22-2-B-B & 29.5 & 1.5 & 76.6 & 6.9 & 97.2 & 137.0 & 9.5 & 70.5 & 21.1 & 25 & 4041 \\
\hline ACCU 16 bar 12-14-19-3-B-B & 22.5 & 1.5 & 79.9 & 6.3 & 84.7 & 134.5 & 7.5 & 65.5 & 18.5 & 22 & 3803 \\
\hline ACCU 16 bar 9-4-16-3-B-1 & 22 & 1.3 & 83.3 & 7.1 & 91.8 & 133.5 & 7.5 & 56.2 & 17.6 & 26 & 2180 \\
\hline ACCU 16 bar 13-13-2-2-B-B & 34.2 & 1.7 & 74.9 & 6.6 & 100.8 & 120.0 & 8.9 & 78.1 & 18.2 & 26 & 3000 \\
\hline ACCU 16 bar 9-7-20-4-B-B & 22.7 & 1.5 & 81.8 & 6.9 & 105.7 & 135.5 & 9.8 & 75.2 & 17 & 26 & 3202 \\
\hline ACCU 16 bar 4-8-17-2-8-8 & 23.1 & 2 & 81.5 & 7.5 & 89.6 & 135.0 & 7.7 & 71.0 & 18.9 & 24 & 2865 \\
\hline NERICA 11 & 28.5 & 1.7 & 88.7 & 11.5 & 101.4 & 133.0 & 8.8 & 79.7 & 19 & 20 & 3408 \\
\hline FOFIFA 3730 & 29 & 1.9 & 80.4 & 7.5 & 92.1 & 138.0 & 7.1 & 71.3 & 18.5 & 25 & 4347 \\
\hline FOFIFA 3737 & 25.5 & 1.8 & 85.9 & 10.6 & 95.2 & 135.0 & 10.8 & 74.8 & 18.1 & 22 & 4434 \\
\hline NERICA 14 & 30.8 & 1.9 & 89.5 & 7.7 & 91.5 & 136.5 & 9.2 & 79.0 & 18.8 & 20 & 4539 \\
\hline NERICA 15 & 22.8 & 1.8 & 73.9 & 11.0 & 92.4 & 134.5 & 6.9 & 74.8 & 22.8 & 23 & 2610 \\
\hline NERICA 8 & 31.7 & 2 & 77.5 & 11.8 & 88.3 & 136.0 & 7.5 & 70.5 & 21.2 & 24 & 3503 \\
\hline NERICA 9 & 23.5 & 1.9 & 69.8 & 8.5 & 89.2 & 135.5 & 8.9 & 61.8 & 20 & 26 & 3517 \\
\hline NERICA 15 & 24.7 & 2 & 77.7 & 7.9 & 88.5 & 135.5 & 10.5 & 90.7 & 18.2 & 23 & 3404 \\
\hline FOFIFA 4129 & 23.5 & 1.5 & 74.4 & 7.4 & 97.2 & 135.5 & 8.5 & 86.8 & 20.7 & 25 & 4364 \\
\hline NERICA 4 (Check) & 23.7 & 1.5 & 73.7 & 11.5 & 87.3 & 133.0 & 8.5 & 62.8 & 17.8 & 29 & 3419 \\
\hline HIDASIE (Check) & 27.5 & 1.5 & 77.8 & 9.9 & 93.1 & 135.0 & 7.5 & 70.7 & 19.5 & 22 & 4471 \\
\hline Mean & 26.3 & 1.7 & 71.56 & 8.58 & 98.36 & 135.39 & 8.79 & 73.45 & 19.5 & 22 & 3895 \\
\hline SE & 0.002 & 0.0057 & 0.058 & 0.17 & 10.08 & 9.70 & 0.23 & 0.46 & 0.03 & 0.013 & 61.3 \\
\hline LSD (1\%) & 9.2 & 0.16 & 1.88 & 0.64 & 6.31 & 6.16 & 0.75 & 1.33 & 1.28 & 2.9 & 620.4 \\
\hline CV $(\%)$ & 2.12 & 4.54 & 1.067 & 4.83 & 3.23 & 2.30 & 5.43 & 0.92 & 2.84 & 4.61 & 6.35 \\
\hline
\end{tabular}

CV (\%): Coefficient of variation, LSD (5\%): Least Significance difference, FLL (cm): Flag leaf length, FLW (cm): Flag leaf width (cm), CL $(\mathrm{cm})$ : Culm length, NTPP: Number of tiller per plant, FC: Flowering cycle, MC: Maturation cycle, NPP: Number of panicle per plant, NSPP: Number of spikelet per panicle, PL(cm): Panicle length, TSW (gm): Thousand seed weight, YLD (kg/ha): Yield 


\subsection{Estimates of Genetic Parameters}

\subsubsection{Estimates of Variance Components}

Number of tillers per plant (22.47\%), number spikelet per panicle (49.98\%), thousand seed weight $(25.56 \%)$ and yield (23.93\%) had higher PCV values. The PCV values for flag leaf length (14.79\%), flag leaf width (16.12\%), and culm length $(16.42 \%)$ and number of panicle per plant $(16.32 \%)$ were medium. Flowering cycle $(7.81 \%)$, maturation cycle (2.9\%), and panicle length (2.5\%) had lower PCV values (Table 5).

GCV values were low for flowering cycle $(7.21 \%)$, maturation cycle $(1.82 \%)$ and panicle length $(2.4 \%)$; medium for flag leaf length (14.26\%), flag leaf width (15.39\%), culm length (15.19\%) and number of panicle per plant $(15.72 \%)$; high for number of tillers per plant $(22.18 \%)$, yield $(23.07 \%)$, thousand seed weight $(25.18 \%)$ and number of spikelet per panicle $(47.60 \%)$. The high GCV values of these characters suggest that genetic impact is higher and lower environmental influences.

Abdusalam et al. (2009) in his study of estimation of genetic variability and correlation for grain yield components in rice found GCV ranged from $0.19 \%$ (grain yield per plant) to $8.32 \%$ (number of grain per plant) and PCV ranged from $0.29 \%$ (grain yield per plant) $8.59 \%$ (Number of grain per plant) which implies lower genetic impact in contrary to this finding.

The difference between PCV and GCV values was high for number of spikelet per panicle (2.38\%), maturation cycle $(1.08 \%)$ and culm length $(1.23 \%)$ which indicated how much the environment influenced these characters. However, this difference was very low for panicle length $(0.1 \%)$, flag leaf length $(0.53 \%)$ and number of tiller per plant $(0.29 \%)$ suggesting minimal influence of environment on the expression of these characters which could be easier to improve these characters through phenotypic selection.

Table 4. Estimate of range, mean, phenotypic (PV) and genotypic (GV) component of variances, broad sense heritability, and genetic advance of parameters.

\begin{tabular}{llllllllll}
\hline Character & Min & Max & Mean & PV & GV & PCV (\%) & GCV (\%) & $\mathbf{h}^{\mathbf{2}(\%)}$ & GA \\
\hline FLL & 19.33 & 34 & 26.02 & 13.9 & 13.78 & 14.79 & 14.26 & 99.13 & 7.59 \\
FLW & 1 & 2.1 & 1.63 & 0.067 & 0.063 & 16.12 & 15.39 & 95.52 & 0.5 \\
CL & 43.33 & 94 & 71.36 & 117.9 & 117.48 & 16.42 & 15.19 & 99.64 & 22.24 \\
NTPP & 5.66 & 13 & 8.398 & 3.56 & 3.47 & 22.47 & 22.18 & 97.47 & 3.78 \\
FC & 85 & 112 & 98.51 & 59.2 & 50.5 & 7.81 & 7.21 & 85.3 & 13.49 \\
MC & 132 & 141 & 135.35 & 15.44 & 6.06 & 2.9 & 1.82 & 39.25 & 3.17 \\
NPP & 6.33 & 12 & 8.57 & 1.96 & 1.815 & 16.32 & 15.72 & 92.84 & 2.67 \\
PL & 52.33 & 93 & 73.26 & 3.34 & 3.115 & 2.5 & 2.4 & 93.12 & 3.50 \\
NSPP & 14 & 23.33 & 19.28 & 84.63 & 84.20 & 49.98 & 47.60 & 99.49 & 18.82 \\
TSW & 7.2 & 37.3 & 24.57 & 39.45 & 38.28 & 25.56 & 25.18 & 97.03 & 12.56 \\
YLD & 1556.5 & 5374.5 & 3895.5 & 869086.6 & 807837 & 23.93 & 23.07 & 92.95 & 45.88 \\
\hline
\end{tabular}

PV: Phenotypic variance, GV: Genotypic variance, PCV(\%): Phenotypic coefficient of variation, GCV(\%): Genotypic coefficient of variation, $\mathrm{h}^{2}(\%)$ : Broad sense heritability, GA(\%): Genetic advance, FLL: Flag leaf length(cm), FLW: Flag leaf width(cm), CL: Culm length(cm), NTPP: Number of tiller per plant, FC: Flowering cycle, MC: Maturation cycle, NPP: Number of panicle per plant, PL: Panicle length(cm), NSPP: Number of spikelet per panicle, TSW: Thousand seed weight(gm), YLD: Yield, Min: Minimum, Max: Maximum

\subsubsection{Estimation of Broad-sense Heritability and Genetic Advance}

Estimates of heritability in broad sense ranged from $39.25 \%$ for maturation cycle to $99.6 \%$ for culm length (Table 5). According to Singh (2001), if heritability of a character is very high, say $80 \%$ or more, selection for such characters could be fairly easy. This is because there would be a close correspondence between the genotype and the phenotype due to the relative small contribution of the environment to the phenotype. But, for characters with low heritability, say $40 \%$ or less, selection may be considerably difficult or virtually impractical due to the masking effect of the environment. Considering this benchmark, heritability estimate was high (>80\%) for all traits except for maturation cycle (39.25\%). Abdusalam et al. (2009) also in his study of estimation of genetic variability and correlation for grain yield components in rice found heritability value of lower than $78 \%$ for all characters studied which is in contrary lower than the findings of this study.

Genetic advance under selection (GA) refers the improvement of characters in genotypic value for the new population compared with the base population under one cycle of selection at a given selection intensity (Singh, 2001). Estimates of GA for seed yield was $45.88 \mathrm{~kg} / \mathrm{ha}$ indicating that selection of the best $5 \%$ high yielding genotypes as parents, mean seed yield of progenies could be improved by $45.88 \mathrm{~kg} / \mathrm{ha}$ for the first cycle i.e., mean genotypic value of the new population for seed yield will be improved from $3895.5 \mathrm{~kg} / \mathrm{ha}$ to $3941.38 \mathrm{~kg} / \mathrm{ha}$. 
Emphasis should be placed on those characters which had high heritability and genetic advance for formulating reliable selection indices for the development of high yielding upland rice genotypes.

According to Johnson et al. (1955) high heritability estimates along with the high genetic advance is usually more helpful in predicting gain under selection than heritability estimates alone. High heritability (99.64\%), (99.49\%) and (92.95\%) coupled with high genetic advance (22.24\%), (18.82\%) and (45.88\%) respectively were observed for culm length, number of spikelets per panicle and grain yield which indicates that these characters could be improved easily than the other characters. Some of the characters had shown high heritability and very low genetic advance i.e., improvement of such traits of the genotypes is difficult.

Parikh et al. (2012) in his study of agro-morphological characterization and assessment of variability in aromatic rice germplasm found that the highest genetic advance was recorded for hundred seed weight (58.15) followed by fertile spikelets per panicle (49.98), spikelet density (44.88), and grain yield per plant (39.73) and high heritability coupled with high genetic advance recorded for fertile spikelets per panicle, spikelet sterility percentage, spikelet density, and grain yield per plant, suggesting preponderance of additive gene action in the expression of these characters which is more or less has similar finding with this study.

\section{Conclusion and Recommendation}

This study generally had indicated that there was significant genetic variability or divergence among the genotypes. Culm length, number of spikelet per panicle and yield were more heritable parameters than others. Thus, there is an enormous opportunity in the improvement program of the upland rice genotypes through direct selection rather than a lengthy crossing program and hybridization which involves technical expertise crossing of the genotypes from different clusters that would produce viable and a potential segregate population. Regarding this, I recommend further study on accessions IR 78937-B-3-B-B-1 for further selection procedures which had the highest yield with a score of $5374.5 \mathrm{~kg} / \mathrm{ha}$ and a yield advantage of $57 \%$ and $22.2 \%$, respectively, as compared to standard checks Nerica-4 and Hidasie.

\section{References}

Abdusalam, K., Mohamed, I., \& Muhammed, A. (2009). Estimation of genetic variability and correlation for grain yield components in rice. American-Erusian J.Agri. and environ. sci., 6(5), 585-590.

Allard, R. W. (1960). Principles of Plant Breeding. John Willey and Sons, New York. p. 485.

Burton, G. W., \& de vane E. H. (1953). Estimating heritability in Tall Fescue (Festuca arundinacea) from replicated clonal material. Agronomy Journal, 45, 481-487. https://doi.org/10.2134/agronj1953.00021962004500100005x

Deshmukh, S. N. S. N., Basu, M. S., \& Reddy, P. S. (1986). Genetic varibailty,character association and path coefficient analysis of quantitative traits in Viginia bunch varieties of ground nut. Indian Journal of Agricultural Science, 56, 515-518.

Johnson, H. W., Robinson, H. F., \& Comstock, R. E. (1955). Estimates of genetic and environmental variability in soybeans. Agronomy Journal, 47, 314-318. https://doi.org/10.2134/agronj1955.00021962004700070009x

Khalid, D., Mustafa, M., \& Husein, J. (2012). Genetic variability for yield and related attributes of upland rice genotypes in semi arid zone. African Journal of Agricultural Research, 7(33), 4613-4619. https://doi.org/10.5897/AJAR12.529

Mulugeta, S. (1999). Effect of mineral N and P fertilizers on yield and yield components of flooded lowland rice on vertisols of Fogera plain, Ethiopia. Agri. and rural dev't, 107, 161-176.

Parikh, M., Motiramani, N. K., Rastogi, N. K., \& Sharma, B. (2012). Agro-morphological characterization and assessment of variability in aromatic rice germplasm. Bangladesh J. Agril. Res., 37(1), 32-36. https://doi.org/10.3329/bjar.v37i1.11168

Singh, B. D. (2001). Plant Breeding: Principles and methods. Kalyani publishers, New Delhi. p. 896.

Veasey, E. A., Silva, E. F., Schammass, E. A., Oliveira, G. C. X., \& Ando, A. (2008). Morph- agronomic genetic diversity in American wild rice. Brazilian Archives of Biology Technology, 51, 99-108.

https://doi.org/10.1590/S1516-89132008000100012 


\section{Copyrights}

Copyright for this article is retained by the author(s), with first publication rights granted to the journal.

This is an open-access article distributed under the terms and conditions of the Creative Commons Attribution license (http://creativecommons.org/licenses/by/4.0/). 